\title{
Long term therapy of cytomegalovirus retinitis with ganciclovir in a child with acquired immunodeficiency syndrome
}

\author{
SCOT A HALPERIN, MD, G ROBERT LA ROCHE, MD
}

\begin{abstract}
SA HALPERIN, GR LA ROCHE. Long term therapy of cytomegalovirus retinitis with ganciclovir in a child with acquired immune deficiency syndrome. Can $J$ Infect Dis 1993:4(1):15-20. Cytomegalovirus retinitis is the most severe ophthalmological complication of patients with acquired immune deficiency syndrome (AIDS). Ganciclovir must be given continuously to control progression of the disease or relapse typically occurs. Data in children are limited; this report describes a nine-year-old boy with transfusionacquired AIDS who was treated with ganciclovir for 23 months for control of cytomegalovirus retinitis. The retinal disease was exacerbated when ganciclovir was temporarily withheld because of presumed drug toxicity, and improved with re-institution of therapy. When ganciclovir was finally discontinued because of complete loss of vision, the patient rapidly deteriorated and died; widespread cytomegalovirus infection was found at autopsy. Subcapsular cataracts appearing during therapy were thought to be a toxic effect of ganciclovir. Ganciclovir can be effective in controlling cytomegalovirus retinitis in children; however, similarities in laboratory findings may lead to confusion between systemic drug toxicity and disease progression.
\end{abstract}

Key Words: Acquired immune deficiency syndrome (AIDS), Cataracts, Cytomegalovirus, Ganciclovir, Retinitis

Traitement à long terme par le ganciclovir d'une rétinite à cytomégalovirus chez un enfant atteint du syndrome d'immunodéficience acquise

\begin{abstract}
RÉSUMÉ: La rétinite à cytomégalovirus (CMV) est la complication ophtalmologique la plus grave qui puisse survenir chez les sidatiques. L'administration continue de ganciclovir est indispensable pour contrôler l'évolution de la maladie, sans quoi les rechutes surviennent typiquement. Les données relatives aux enfants sont limitées. Le présent rapport décrit le cas d'un garçon âgé de neuf ans, ayant contracté le SIDA à la suite d'une transfusion sanguine, et qui a été traité par le ganciclovir pendant 23 mois pour contrôler une rétinite à cytomégalovirus. La maladie a été exacerbée par l'arrêt temporaire du médicament, motivé par sa présumée toxicité, et améliorée dès la reprise du traitement. Quand la thérapie a été définitivement interrompue en raison d'une cécité totale, l'état du patient s'est rapidement détérioré et il est décédé. L'étendue de l'infection à CMV a été constatée à l'autopsie. Les cataractes sous-capsulaires apparues au cours du traitement sont attribuées à l'effet toxique du ganciclovir. Le médicament peut contrôler efficacement la rétinite à CMV chez l'enfant. Cependant, la similarité des résultats de laboratoire peut créer une confusion entre une toxicité médicamenteuse systémique et l'évolution de la maladie.
\end{abstract}

Departments of Pediatrics, Ophthalmology, and Microbiology, Dalhousie University: and the Izaak Walton Killam Hospital for Children, Halifax, Nova Scotia.

Correspondence and reprints: Dr Scott A Halperin. Izaak Walton Killam Hospital for Children, 5850 University Avenue, Halifax, Nova Scotia B3J 3G9. Telephone (902) 428-8498

Received for publication February 1, 1991. Accepted October 28, 1991 
$\mathrm{T}$ HE NUMBER OF CHILDREN INFECTED BY THE HUMAN immunodeficiency virus (HIV) continues to increase in Canada and throughout the world $(1,2)$. Like adults, children with the acquired immune deficiency syndrome (AIDS) are susceptible to opportunistic infections (3). Substantial morbidity and mortality are associated with infection by cytomegalovirus (CMV) which may cause retinitis, enteritis, pneumonitis and hepatitis $(4,5)$. Recently ganciclovir (Cytovene; Syntex), an antiviral drug which is active against CMV, was licensed for use in Canada. There has been limited experience with this agent in children, and the optimal parameters for its use are unknown. The authors report the long term use of ganciclovir in a child with AIDS complicated by CMV retinitis. The difficulty in differentiating drug-induced systemic toxicity from progression of CMV disease is discussed, and the development of subcapsular cataracts as a possible toxic complication of long term therapy is described.

\section{CASE PRESENTATION}

An eight-year-old boy, previously treated for acute lymphoblastic leukemia, developed fatigue, weight loss, adenopathy and elevated hepatic enzymes over a two month period. A diagnostic evaluation revealed positive HIV serology. The infection was traced to an HIV-positive unit of erythrocytes received 15 months before.

One month later, the patient developed Candida albicans esophagitis. Retinal lesions in the left eye and localized disk swelling were thought to be early candida endophthalmitis. He was treated with amphotericin B and flucytosine for one month until hepatic enzyme elevation necessitated discontinuation of therapy. The retina were normal at that point. Three months later, the patient developed bilateral CMV retinitis with visual loss in both eyes. Macular involvement was worse in the left eye and was accompanied by papillitis and retinitis (Figure la). Vision was markedly decreased in that eye while the paramacular location of the main focus of disease allowed better vision in the right eye. Ganciclovir $2.5 \mathrm{mg} / \mathrm{kg}$ every $8 \mathrm{~h}$ for four weeks produced marked improvement in the appearance of the fundus and some recovery of visual acuity (Figure lb). CMV cultures of upper respiratory tract secretions and urine reverted to negative. Ganciclovir therapy was changed to a maintenance dosage of $6 \mathrm{mg} / \mathrm{kg} /$ day for five days. Therapy was interrupted at week 12 in response to a rise in hepatic enzymes. CMV cultures of urine, blood and pharyngeal secretions were negative.

Ganciclovir was again discontinued at week 30 because of pancytopenia. However, when CMV was recovered from cultures of blood, urine and throat, ganciclovir was reinstituted at the maintenance dose and schedule. Elevated hepatic enzymes and thrombocytopenia again led to discontinuation of ganciclovir at week 41 of therapy. A relapse of retinitis and vitritis in the left eye and diffuse retinal ischemic changes in the right eye ensued leaving vision severely impaired in both eyes. Ganciclovir was restarted at $6 \mathrm{mg} / \mathrm{kg}$ for five days per week but was increased to $5 \mathrm{mg} / \mathrm{kg}$ every 12 h 10 days later when pulmonary infiltrates and fever developed and CMV was recovered from respiratory secretions collected at bronchoscopy. The pulmonary infiltrates resolved, visual acuity improved, and there was a decrease in activity of the retinal lesions. Pancytopenia improved and hepatic enzymes decreased.

Over the next five months, the patient was clinically well with weight gain and increased activity. Ganciclovir was continued at $6 \mathrm{mg} / \mathrm{kg}$ once daily. There was no significant deterioration in visual acuity nor reactivation of the retinal lesions. Hematological and hepatic laboratory parameters were stable. During week 70 of therapy, bilateral posterior subcapsular cataracts were first detected despite both eyes having been otherwise quiescent for six months (Figure lc).

After 95 weeks of ganciclovir therapy, the patient developed congestive heart failure which was treated with digitalis and diuretics. Diffuse retinitis and increased cataracts were noted in the right eye; an opaque lens and hazy media completely obscured the left fundus. The left eye had no light perception while the right eye was limited to a small peripheral island of vision. CMV was recovered from a urine culture.

The patient developed worsening congestive heart failure and nephrosis during week 98 and was anemic and thrombocytopenic. Because of total vision loss, ganciclovir was discontinued. Interstitial pneumonia developed eight days later and rapidly progressed over the next five days. Worsening cardiac dysfunction and renal failure led to the patient's death 100 weeks after initiation of ganciclovir therapy. A post mortem examination showed widespread CMV disease involving the kidneys, lungs, brain, retina, heart, liver and bowel (Figure 2).

\section{DISCUSSION}

CMV retinitis is the most severe ophthalmological complication of patients with AIDS $(6,7)$. Ganciclovir, an acyclovir analogue active against CMV, is now widely used for therapy of CMV retinitis, but data in children are limited. This report described a child with transfusion-acquired AIDS and CMV retinitis treated with ganciclovir for 23 months.

CMV is an important opportunistic pathogen and a major cause of death in children with AIDS. Clinical manifestations of CMV infection include disseminated infection, gastric ulceration, hepatitis, encephalitis and interstitial pneumonia (3). CMV retinitis typically is a progressive, necrotizing lesion which may be bilateral and multifocal. Lesions may begin as diffuse retinitis with multiple hemorrhages or as focal areas that gradually increase in size leaving an atrophic centre (8). Necrotic lesions often are surrounded by retinal hemorrhage. The optic nerve may be involved (9). Loss of 

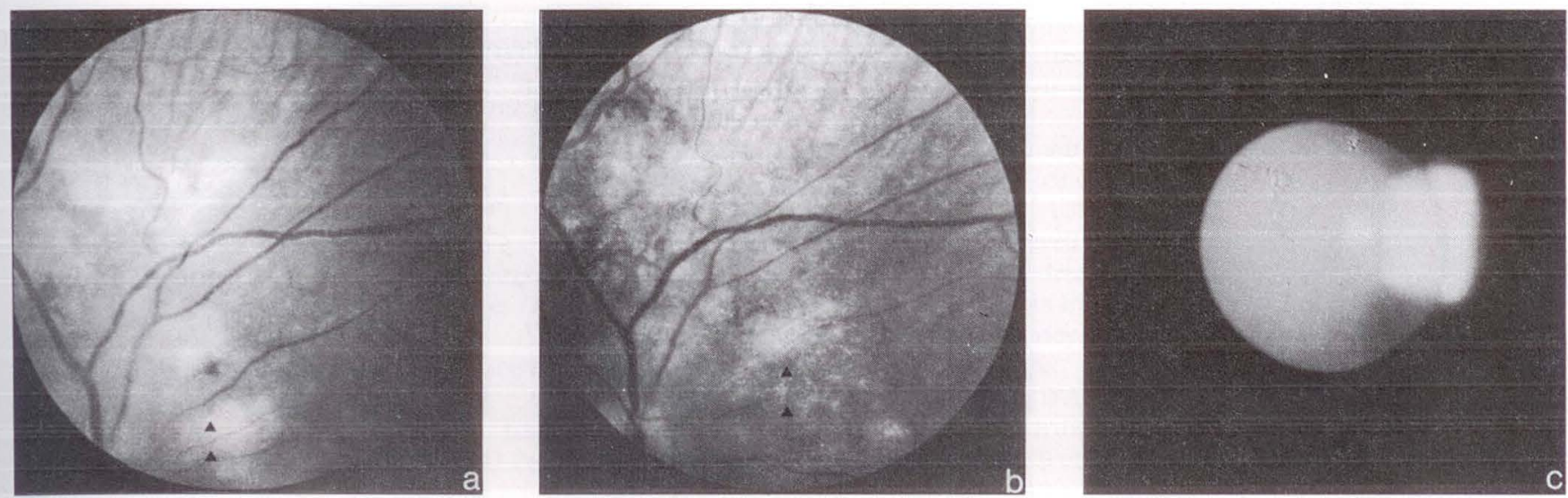

Figure 1) Ophthalmological findings of CMV infection treated long term with ganciclovir. a Left fundus showing acute necrotizing CMV retinitis before treatment. $\mathbf{b}$ After initial treatment, the lesions have almost disappeared leaving behind thinned area of retina with sclerotic vessels. $\mathbf{c}$ Right lens showing early vesicular posterior lenticular changes attributable to the chronic use of ganciclovir

visual acuity is related mainly to macular and optic nerve involvement. Vitreous involvement may occur and retinal detachment is a common late complication (10). While retinitis alone in CMV infection is observed in 15 to $46 \%$ of AIDS patients (8), it occurs less commonly in children than adults (11). However, ocular involvement in disseminated CMV infection is more common in children (7).

Ganciclovir is an acyclic nucleoside analogue of $2^{\prime}$ deoxyguanosine with potent anti-CMV activity in vitro and in vivo. The mechanism of action is selective inhibition of CMV DNA polymerase $(12,13)$, thus effectively inhibiting viral replication. Bone marrow suppression, including anemia, neutropenia and thrombocytopenia, is the most common adverse reaction which limits the use of ganciclovir. Other toxic reactions include hepatocellular damage, rash, gastrointestinal symptoms and neurological abnormalities including disorientation, confusion and psychosis (14).

Cataracts have not previously been reported as a toxic effect of ganciclovir. While posterior cataracts secondary to chronic inflammation associated with CMV infection could have occurred in the present patient, they appeared when the ocular CMV infection had been quiescent for many months. Furthermore, cataracts have not previously been reported in chronic CMV eye infections of HIV-infected patients. The early stages of the present patient's cataracts could have been mistaken for steroid-induced opacities but their appearance was not characteristic, and while steroids had been given during the patient's leukemia therapy, the intermittent courses of five days' duration had been completed 25 months before the appearance of the cataracts. A longer course of daily steroids was also administered during induction chemotherapy, but it was completed four-and-a-half years before development of the cataracts. The length of the intervening delays precludes implication of the steroids in the cataracts' formation (15).

The duplicating lens epithelium of a child likely is more susceptible than an adult's to ganciclovir, similar to the increased susceptibility of young lenses to radiation. Radiation cataracts appear to be caused by alterations in the protein metabolism of cell division (16), probably the same mechanism of cataractogenesis occurring with ganciclovir, a DNA polymerase inhibitor. Radiation primarily damages the germinative epithelial cells of the lens; therefore, cataracts would occur with lesser radiation doses and with a shorter latency period in younger lenses. Moreover, the earlier changes of experimental radiation cataracts have shown vacuoles of the posterior lens similar to those in the present patient (Figure lc) who was never given radiotherapy.

Numerous studies have demonstrated the usefulness of ganciclovir for the treatment of CMV retinitis in adults (17-26) and less commonly in children (27). Response to ganciclovir therapy has exceeded $80 \%$ in most studies using two to three weeks of therapy at 7.5 to $10 \mathrm{mg} / \mathrm{kg}$, but the retinitis recurred by three weeks in virtually all patients after ganciclovir was discontinued. For this reason, lifelong maintenance therapy has been recommended $(17,20,21,25,26)$.

Long term therapy delays but does not halt progression of retinitis $(28,29)$. Ganciclovir is a virostatic agent which inhibits replication but does not eradicate the virus. Although retinal lesions regress with therapy, active CMV lesions can be demonstrated at margins of scars, and in other ocular tissue of ophthalmologically normal fundal areas (30-32). The emergence of viral resistance to ganciclovir in patients on long term therapy has also been a concern since the in vitro isolation of a resistant viral mutant (33) and the more recent report of resistance in the clinical setting (34). Longer duration of therapy is associated with an increased incidence of resistance (35).

Progression of the CMV retinitis in this case study occurred despite maintenance ganciclovir therapy, while acceleration of the retinal disease was related to temporary discontinuation of antiviral therapy made necessary because of concerns about potential drug 

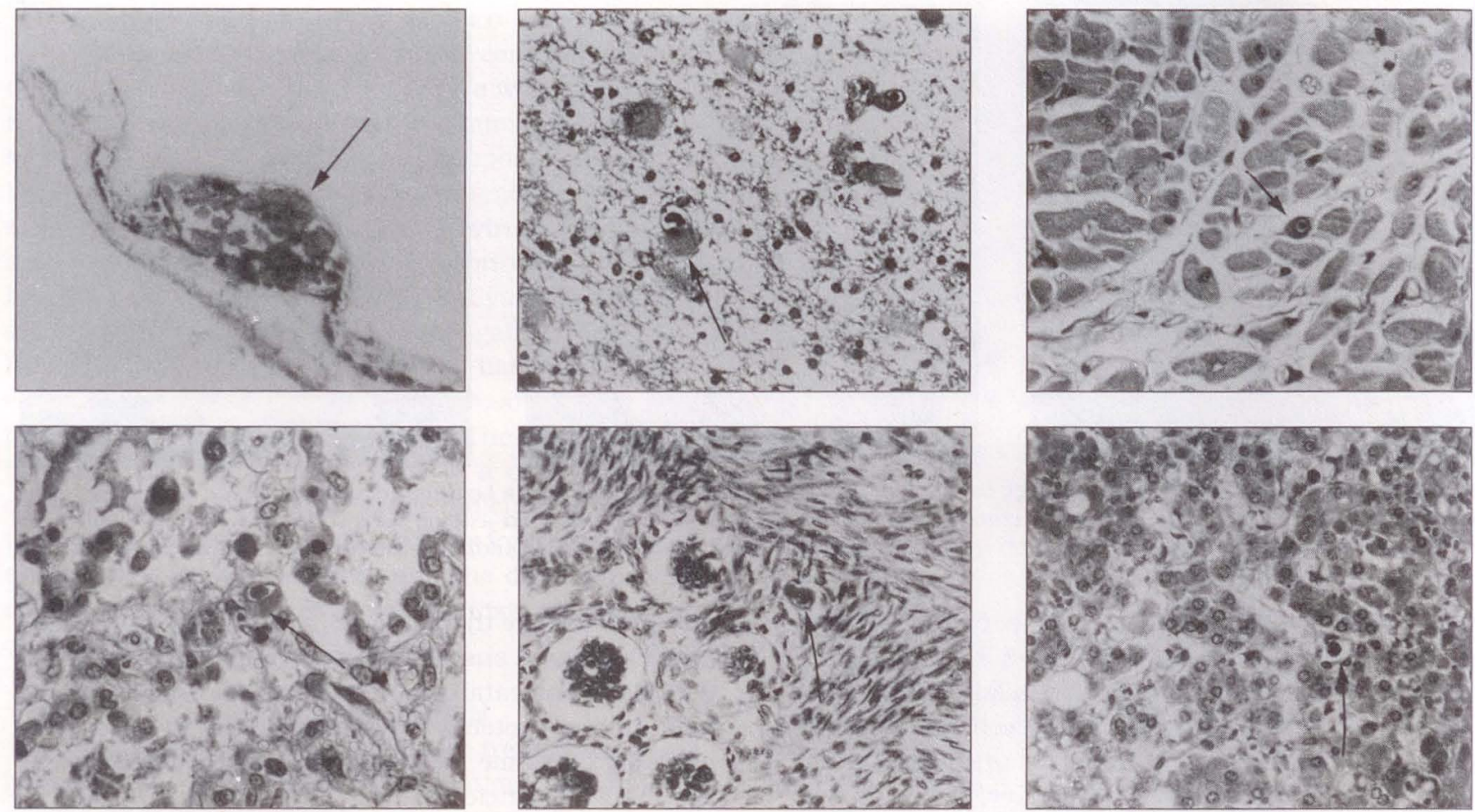

Figure 2) Histological involvement with CMV infection (hematoxylin and eosin stain). Top left Endstage calcification (arrow) of the retina reflects severe damage to the eye caused by CMV (60x). Top centre Periventricular destruction associated with giant astrocytes, often with CMV intranuclear inclusions (arrow) (250x). Top right CMV inclusions (arrow) in myocytes of the heart (250x). Bottom left Diffuse alveolar pulmonary damage with CMV inclusion (arrow) (250x). Bottom centre CMV inclusions (arrow) in bowel, probably in endothelium of submucosal capillary (250x). Bottom right Hepatic inclusions (arrow) associated with extensive fatty change, lobular disarray, and degeneration (250x)

toxicity. The difficulty in distinguishing commonly reported ganciclovir adverse effects (neutropenia, hepatic enzyme elevation) from systemic CMV disease repeatedly led to trials of drug withdrawal followed by more intensive drug therapy. Although this approach may have prevented irreversible drug toxicity, the cost was rapid and mostly irreversible loss of visual acuity. Histopathological liver examination might have provided a specific diagnosis but this procedure is not without risk. The etiology of neutropenia in HIV-infected individuals often is resistant to specific diagnosis (36).

Alternative methods of drug delivery have been proposed to circumvent the systemic toxicity of ganciclovir. Repeated intravitreal ganciclovir has been used successfully for CMV retinitis (37-39). This approach has permitted the use of ganciclovir in patients who have bone marrow suppression due to underlying disease, previous ganciclovir therapy or use of other myelosuppressive drugs, such as zidovudine. However, there are many disadvantages of intravitreal injections of ganciclovir including the loss of systemic antiviral activity (40) and difficulty of the necessary repeated intravitreal injections in children. Although ganciclovir therapy has been less effective in treating CMV infections in organs other than the retina (41-45), delayed progression of the disease has frequently been reported. Foscarnet (trisodium phosphonoformate) is an investigational antiviral drug which may be effective in patients with $\mathrm{CMV}$ retinitis whose $\mathrm{CMV}$ isolates have developed resistance to ganciclovir (46). In this study, however, the rapid deterioration and death following discontinuation of ganciclovir, and the disseminated infection found at post mortem examination suggests that the ganciclovir may still have been providing some antiviral effect at the time of its discontinuation, despite progression of the ocular disease. Unfortunately the virus could not be reisolated from frozen aliquots for ganciclovir susceptibility testing.

As the number of HIV-infected children grows, adequate management of serious CMV infection will become more important. Although limited by its significant toxicity, parenteral route and requirement for lifelong therapy, ganciclovir is the only licensed antiviral agent with demonstrated efficacy in treating CMV disease (47). Additional experience with its use in children is required to establish the optimal therapeutic and maintenance regimen and to define the most effective ophthalmological assessment schedule. This report has demonstrated that ganciclovir can be used effectively in a child for a prolonged period and may slow progression of the disease in absence of a full remission. Long term use of ganciclovir, however, can have a toxic effect on children's ocular lenses. The authors emphasize the need for improved methods to distinguish drug toxicity from manifestations of CMV infection and the need for frequent ophthalmological examination of HIV-infected children. 
ACKNOWLEDGEMENTS: We thank Christine Fern for the preparation of the manuscript and Dr Eva Mikhail and the Pathology Department of the Izaak Walton Killam Children's Hospital for preparation and interpretation of the histological sections.

\section{REFERENCES}

1. Oxtoby MJ. Perinatally acquired human immunodeficiency virus infection. Pediatr Infect Dis $\mathrm{J}$ 1990;9:609-19.

2. Federal Centre for AIDS. AIDS surveillance in Canada. CDWR 1990;16:93-5

3. Falloon J, Eddy J, Wiener L, Pizzo PA. Human immunodeficiency virus infection in children. J Pediatr 1989:114:1-30.

4. Schooley RT. Cytomegalovirus in the setting of infection with human immunodeficiency virus. Rev Infect Dis 1990;12:S811-9.

5. Frenkel LD, Gaur S, Tsolia M, Scudder R, Howell R, Kesarwala H. Cytomegalovirus infection in children with AIDS. Rev Infect Dis 1990;12:S820-6.

6. Palestine AG, Rodrigues MM, Macher AM, et al. Ophthalmic involvement in acquired immunodeficiency syndrome. Ophthalmology 1984;91:1092-9.

7. Dennehy PJ, Warman R, Flynn JT, Scott CB, Mastrucci MT. Ocular manifestations in pediatric patients with acquired immunodeficiency syndrome. Arch Ophthalmol 1989;107:978-82.

8. Palestine AG. Clinical aspects of cytomegalovirus retinitis. Rev Infect Dis 1988;10:S515-21.

9. Grossniklaus HE, Frank KE, Tomsak RL. Cytomegalovirus retinitis and optic neuritis in acquired immune deficiency syndrome - report of a case. Ophthalmology 1987;94:1601-4.

10. Gross JG, Bozzette SA, Matthews WC, et al. Longitudinal study of cytomegalovirus retinitis in acquired immune deficiency syndrome. Ophthalmology 1990;97:681-6.

11. Levin AV, Zeichner S, Duker JS, Starr SE, Augsburger JJ, Kronwith S. Cytomegalovirus retinitis in an infant with acquired immunodeficiency syndrome. Pediatrics 1989;84:683-7.

12. Matthews T, Boehme R. Antiviral activity and mechanism of action of ganciclovir. Rev Infect Dis 1988;10:S490-4.

13. Verheyden JPH. Evolution of therapy for cytomegalovirus infection. Rev Infect Dis 1988;10:S477-89.

14. Buhles WC Jr, Mastre BJ, Tinker AJ, Strand V, Koretz SH and The Syntex Collaborative Ganciclovir Treatment Study Group. Ganciclovir treatment of life- or sightthreatening cytomegalovirus infection: Experience in 314 immunocompromised patients. Rev Infect Dis 1988;10:S495-506.

15. Paterson CA. The crystalline lens. In: Tasman W, Jaeger EA, eds. Duane's Foundations of Clinical Ophthalmology. Philadelphia: JB Lippincott, 1990;2:18-9.

16. Fournier C, Milot JA, Clermont MJ, O'Regan S. The concept of corticosteroid cataractogenic factor revisited. Can J Ophthalmol 1990;25:345-7.

17. Henderly DE, Freeman WR, Causey DM, Rao NA. Cytomegalovirus retinitis and response to therapy with ganciclovir. Ophthalmology 1987;94:425-34.

18. Macdonald EA. Treatment of cytomegalovirus retinitis in a patient with AIDS with 9-(1,3-dihydroxy-2-propoxymethyl)guanine. Can J Ophthalmol 1987;22:48-52.

19. Palestine AG, Stevens G Jr, Lane HC, et al. Treatment of cytomegalovirus retinitis with dihydroxy propoxymethyl guanine. Am J Ophthalmol 1986;101:95-101.

20. Orellana J, Teich SA, Friedman AH, Lerebours F,
Winterkorn J, Mildvan D. Combined short- and long-term therapy for the treatment of cytomegalovirus retinitis using ganciclovir (BW B759U). Ophthalmology 1987;94:831-8.

21. Jabs DA, Newman C, De Bustros S, Polk BF. Treatment of cytomegalovirus retinitis with ganciclovir. Ophthalmology 1987;94:824-30.

22. Bach MG, Bagwell SP, Knapp NP, Davis KM, Hedstrom PS. 9-(1,3-dihydroxy-2-propoxymethyl)guanine for cytomegalovirus infections in patients with the acquired immunodeficiency syndrome. Ann Intern Med 1985; 103:381-2.

23. Felsenstein D, D'Amico DJ, Hirsch MS, et al. Treatment of cytomegalovirus retinitis with 9-[2-hydroxy-1(hydroxymethyl) ethoxymethyl]guanine. Ann Intern Med 1985; 103:377-80.

24. Holland GN, Sakamoto MJ, Hardy D, et al. Treatment of cytomegalovirus retinopathy in patients with acquired immunodeficiency syndrome: Use of the experimental drug 9-[2-hydroxy-1-(hydroxymethyl(ethoxymethyl) guanine. Arch Ophthalmol 1986;104:1794-800.

25. Holland GN, Sidikaro Y, Kreiger AE, et al. Treatment of cytomegalovirus retinopathy with ganciclovir. Ophthalmology 1987;94:815-23.

26. Rosecan LR, Stahl-Bayliss CM, Kalman CM, Laskin OL. Antiviral therapy for cytomegalovirus retinitis in AIDS with dihydroxy propoxymethyl guanine. Am J Ophthalmol 1986;101:405-18.

27. Rosecan LR, Laskin OL, Kalman CM, Haik BG, Ellsworth RM. Antiviral therapy with ganciclovir for cytomegalovirus retinitis and bilateral exudative retinal detachments in an immunocompromised child. Ophthalmology 1986;93:1401-7.

28. Jacobson MA, O'Donnell JJ, Brodie HR, Wofsy C, Mills J. Randomized prospective trial of ganciclovir maintenance therapy for cytomegalovirus retinitis. J Med Virol 1988:25:339-49.

29. Mills J, Jacobson MA, O'Donnell JJ, Cederberg D, Holland GN. Treatment of cytomegalovirus retinitis in patients with AIDS. Rev Infect Dis 1988;10:S522-31.

30. Teich SA, Castle J, Friedman AH, Siroty W, Orellana J, Schmitterer M. Active cytomegalovirus particles in the eyes of an AlDs patient being treated with 9-[2-hydroxy-1-(hydroxymethyl)ethoxymethyl] guanine (ganciclovir). Br J Ophthalmol 1988;72:293-8.

31. D'Amico DJ, Talamo JH, Felsenstein D, Hirsch MS, Albert DM, Schooley RT. Ophthalmoscopic and histologic findings in cytomegalovirus retinitis treated with BW-B759U. Arch Ophthalmol 1986;104:1788-93.

32. Pepose JS, Newman C, Bach MC, et al. Pathologic features of cytomegalovirus retinopathy after treatment with the antiviral agent ganciclovir. Ophthalmology 1987:94:414-24.

33. Biron KK, Fyfe JA, Stanat SC, et al. A human cytomegalovirus mutant resistant to the nucleoside analog 9-([2-hydroxy-1-(hydroxymethyl)-ethoxymethyl)guanine (BW B759U) induces reduced levels of BW B759U triphosphate. Proc Natl Acad Sci 1986:83:8769-73.

34. Erice A, Chou S, Biron KK, Stanat SC, Balfour HH Jr, Jordan MC. Progressive disease due to ganciclovir-resistant cytomegalovirus in immunocompromised patients. N Engl J Med 1989;320:289-93.

35. Drew WL, Miner RC, Busch DF, et al. Prevalence of resistance in patients receiving ganciclovir for serious cytomegalovirus infection. J Infect Dis 1991;163:716-9.

36. Butler KM. Hematologic manifestations of HIV infection. In: Pizzo PA, Wilfert CM, eds. Pediatric AIDS - The 
Challenge of HIV Infection in Infants, Children, and Adolescents. Maryland: Williams \& Wilkins, 1991;31:430-7.

37. Henry K, Cantrill H, Fletcher C, Chinnock BJ, Balfour HH Jr. Use of intravitreal ganciclovir (dihydroxy propoxymethyl guanine) for cytomegalovirus retinitis in a patient with AIDS. Am J Ophthalmol 1987; 103:17-23.

38. Cantrill HL, Henry K, Melroe NH, Knobloch WH, Ramsay $\mathrm{RC}$, Balfour HH Jr. Treatment of cytomegalovirus retinitis with intravitreal ganciclovir: Long-term results. Ophthalmology 1989;96:367-74.

39. Ussery FM III, Gibson SR, Conklin RH, Plot DF, Stool EW, Conklin AJ. Intravitreal ganciclovir in the treatment of AIDS-associated cytomegalovirus retinitis. Ophthalmology 1988;95:640-8.

40. Holland GN. Discussion: Intravitreal ganciclovir in CMV retinitis. Ophthalmology 1991;98:1353-55.

41. Dieterich DT, Chachoua A, Lafleur F, Worrell C. Ganciclovir treatment of gastrointestinal infections caused by cytomegalovirus in patients with AIDS. Rev Infect Dis 1988; 10:S532-7.

42. Crumpacker C, Marlowe S, Zhang JL, Abrams S, Watkins
P and The Ganciclovir Bone Marrow Transplant Treatment Group. Treatment of cytomegalovirus pneumonia. Rev Infect Dis 1988;10:S538-46.

43. Chachoua A, Dieterich D, Krasinski K, et al. 9-(1,3-dihydroxy-2-propoxymethyl) guanine (ganciclovir) in the treatment of cytomegalovirus gastrointestinal disease with the acquired immunodeficiency syndrome. Ann Intern Med 1987; 107:133-7.

44. Laskin OL, Cederberg DM, Mills J, Eron LJ, Mildvan D, Spector SA. Ganciclovir for the treatment and suppression of serious infections caused by cytomegalovirus. Am J Med 1987;83:201-7.

45. Masur H, Lane HC, Palestine A, et al. Effect of 9-(1,3-dihydroxy-2-propoxymethyl) guanine on serious cytomegalovirus disease in eight immunosuppressed homosexual men. Ann Intern Med 1986;104:41-4.

46. Jacobson MA, Drew WL, Feinberg J, et al. Foscarnet therapy for ganciclovir-resistant cytomegalovirus retinitis in patients with AIDS. J Infect Dis 1991;163:1348-51.

47. Balfour HH Jr. Management of cytomegalovirus disease with antiviral drugs. Rev Infect Dis 1990;12:S849-60. 


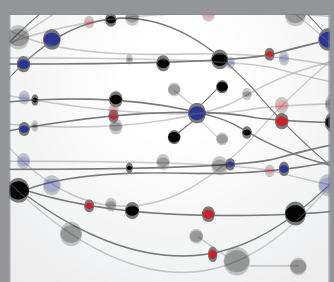

The Scientific World Journal
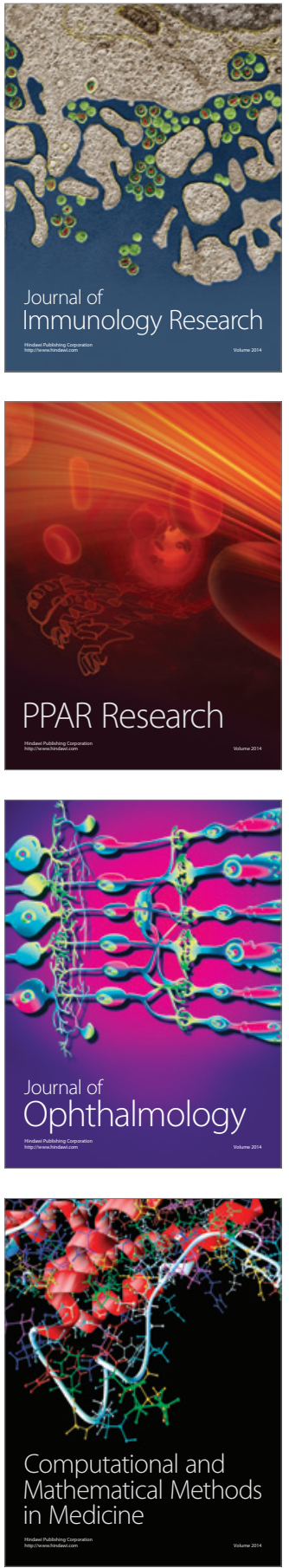

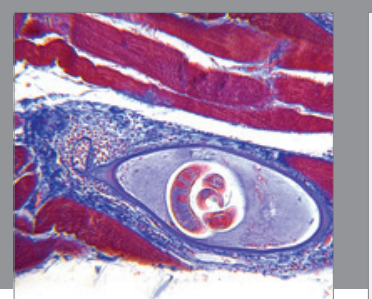

Gastroenterology Research and Practice

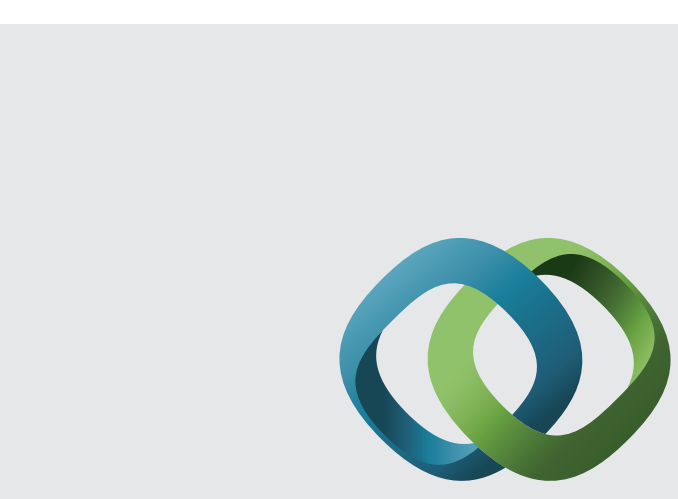

\section{Hindawi}

Submit your manuscripts at

http://www.hindawi.com
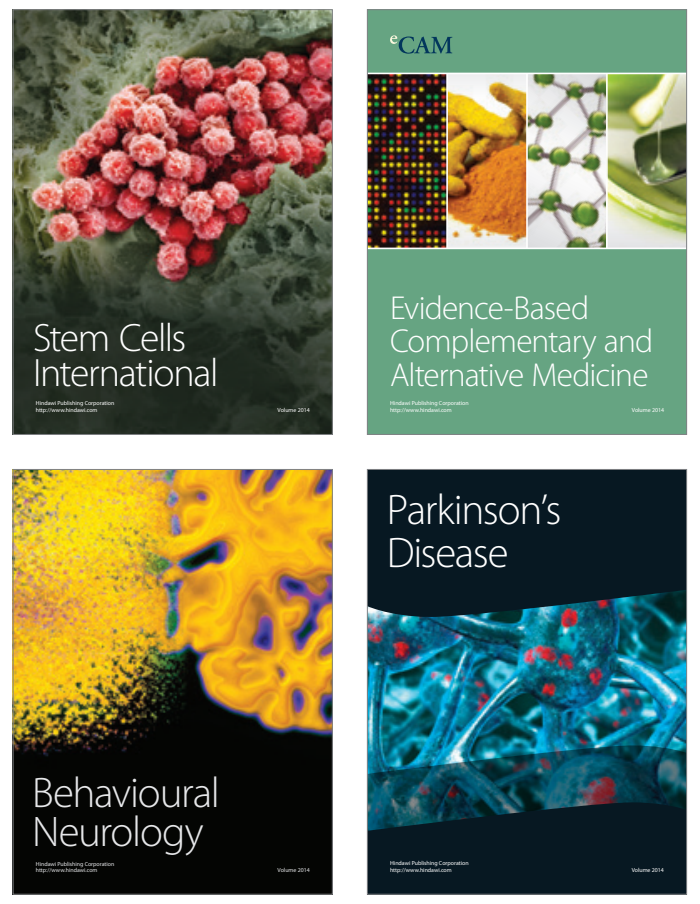
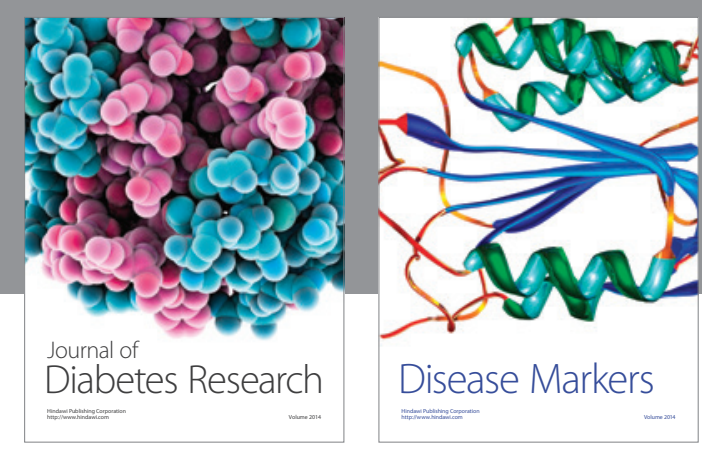

Disease Markers
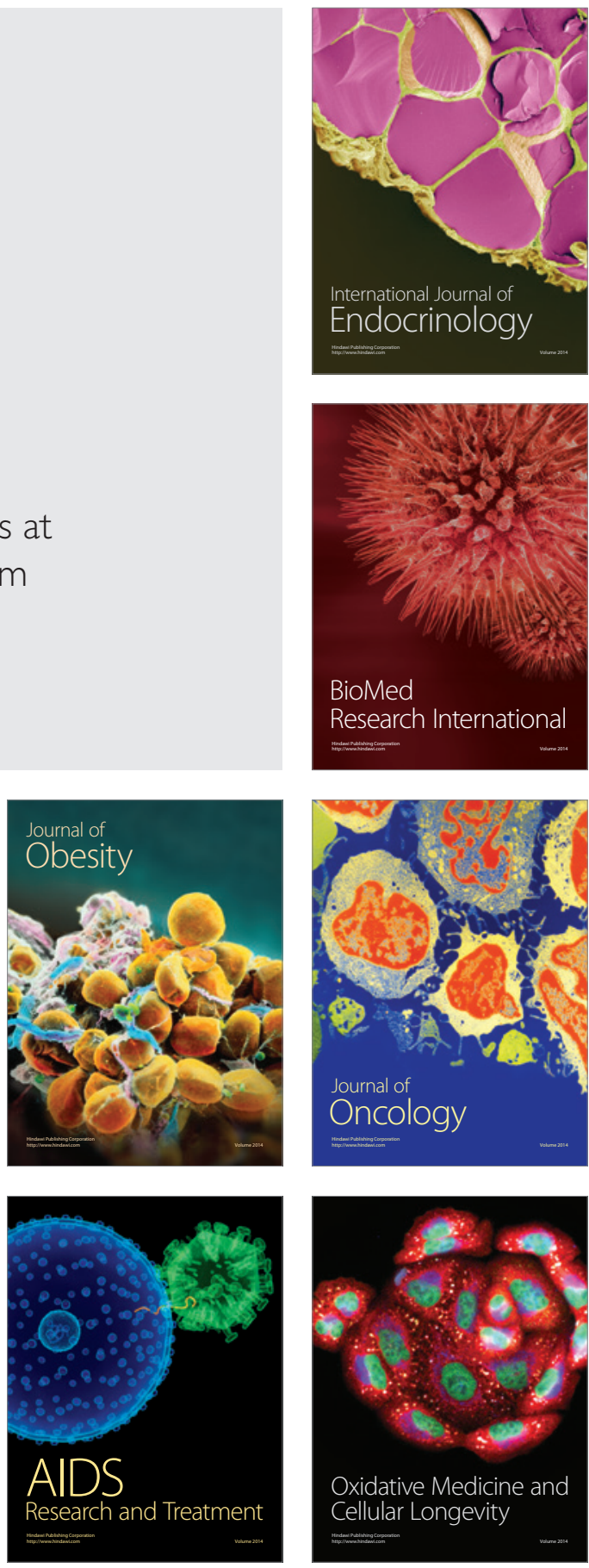